\title{
SINERGIA
}

REVISTA DO INSTITUTO DE CIÊNCIAS ECONÔMICAS, ADMINISTRATIVAS E CONTÁBEIS (ICEAC)

\section{MOTIVAÇÃO DOS ACADÊMICOS DE CIÊNCIAS CONTÁBEIS DE UMA UNIVERSIDADE PÚBLICA}

\author{
DIONE DOS SANTOS \\ JULIANE ANDRESSA PAVÃO** \\ IASMINI MAGNES TURCI BORGES
}

RESUMO

\begin{abstract}
A motivação tem sido discutida no contexto educacional do ensino superior, pois têm implicações diretas em relação à qualidade do envolvimento do acadêmico para a entrada e permanência no curso. Consoante a isso, o estudo tem como objetivo analisar os interesses motivacionais dos acadêmicos de Ciências Contábeis da Universidade Estadual do Paraná (UNESPAR) - campus de Campo Mourão para entrada e permanência no curso. Metodologicamente, tratase de um estudo descritivo e quantitativo, com coleta de dados realizada por meio de uma survey, sendo utilizado estatística descritiva, correlação de pearson e regressão linear múltipla para análise dos dados. Houve a participação de 168 acadêmicos. Percebe-se que os acadêmicos investigados têm boa relação com colegas, professores e instituição, que são motivados intrinsecamente e extrinsecamente, e ainda os acadêmicos atribuíram boas notas para a avaliação que fizeram de si próprio. Além disso, não foi identificado um alto nível de desmotivação nos estudantes investigados. Os resultados apontam que a quanto maior a desmotivação de um estudante, menor será sua auto avaliação de desempenho. E ainda, o fato de se identificar com o curso, a necessidade de provar a si mesmo sua capacidade e o anseio de retorno financeiro influenciam positivamente na auto avaliação de desempenho dos estudantes de contabilidade investigados. Esse estudo traz contribuições teóricas e práticas, uma vez que adota a teoria da autodeterminação para compreender melhor os níveis e tipos de motivação dos estudantes de contabilidade e seus efeitos na auto avaliação do desempenho.
\end{abstract}

Palavras-chave: Ciências Contábeis; Motivação; Acadêmicos.

\section{ABSTRACT}

Motivation has been discussed in the educational context of higher education, as it has direct implications in relation to the quality of the academic's involvement in entering and remaining in the course. Accordingly, the study aims to analyze the motivational interests of accounting students at the State University of Paraná (UNESPAR) - Campo Mourão campus for entry and stay in the course. Methodologically, it is a descriptive and quantitative study, with data collection performed through a survey, using descriptive statistics, Pearson's correlation and multiple linear regression for data analysis. 168 academics participated. It is noticed that the investigated academics have a good relationship with colleagues, professors and institutions, who are intrinsically and extrinsically motivated, and the academics also assigned good marks for the assessment they made of themselves. In addition, a high level of demotivation was not identified in the investigated students. The results show that the greater the demotivation of a student, the lower his self-assessment of performance. In addition, the fact of identifying with the course, the need to prove yourself your ability and the desire for financial return positively influence the self-assessment of performance of the accounting students investigated. This study brings theoretical and practical contributions, since it adopts the theory of selfdetermination to better understand the levels and types of motivation of accounting students and their effects on performance self-assessment.

Keywords: Accounting Sciences; Motivation; Students.

Recebido em: 27-04-2020 Aceito em: 12-06-2020

\section{INTRODUÇÃO}

A educação é um processo de aprendizagem no qual permite que indivíduos se integrem no mercado de trabalho, convivam em grupo, se tornem críticos na sociedade. Nesse sentido, há uma preocupação com a qualidade da educação no Brasil, seja no ensino básico ou superior, que se encontra com grandes índices de evasão, violência, desinteresse e reprovação escolar (OLIVEIRA, 2017).

Psicólogos, pedagogos, psicopedagogos, sociólogos, e órgãos relacionados à educação, que

\footnotetext{
Graduado em Ciências Contábeis pela Universidade Estadual do Paraná Campus de Campo Mourão. E-mail: dione02012015@gmail.com

" Mestra em Ciências Contábeis pela Universidade Estadual de Maringá. Professora da Universidade Estadual de Maringá

"*** Mestra em Ciências Contábeis pela Universidade Estadual de Maringá.
} 
mediante estudos e implantação de novas propostas pedagógicas, têm procurado verificar os fatores que interferem no sucesso escolar dos alunos, visando melhorar a atual situação do ensino nacional (NEVES; BORUCHOVITCH, 2004). Se tratando do ensino superior, docentes queixam-se que muitos acadêmicos demonstram pouco interesse e baixo rendimento (OLIVEIRA, 2017), o que pode ser consequência da falta de motivação.

Motivar está relacionado a modificar, mudar, impulsionar, estar em movimento, rumar para um objetivo a ser alcançado. Pode ser compreendida como algo que impele a pessoa a ter determinado comportamento ou atitude em relação à circunstância em que se encontra (OLIVEIRA, 2017). No mundo acadêmico, a motivação é determinante para o alto desempenho e para a boa qualidade da aprendizagem. Estudantes motivados são participativos e ativos, procuram sempre mais informações, se esforçam e se dedicam para desenvolver melhores estratégias em busca da compreensão e do domínio dos conteúdos (RAMOS, 2013). Compreender a motivação dos acadêmicos é essencial para ter um melhor aproveitamento do ensino e de formar profissionais mais qualificados para sociedade.

De acordo com Oliveira (2017), não só existe uma carência de interesse e rendimento por grande parte dos universitários, como também, identifica-se uma deficiência em relação à qualidade de ensino e de aprendizagem nos cursos superiores. Para Ruiz (2004), "não há uma preocupação em conservar a motivação do universitário e tampouco em diminuir as dificuldades de aprendizagem" (p. 173). Ademais, há poucos anos, ainda existia a percepção de que apenas ter um vasto conhecimento na área de atuação tornava o docente um bom profissional e não era necessário que o ensino se desse de forma contextualizada e didática. Hoje, a importância da motivação no contexto escolar tem sido reforçada e reconhecida pelos docentes (OLIVEIRA, 2017).

É necessário formar profissionais capacitados e motivados com sua profissão, visto que o mercado de trabalho, cada vez mais, tem buscado profissionais com alto nível de conhecimento e qualidade (DIAS; MOREIRA, 2008). E a motivação universitária deve ter início no ingresso do acadêmico. Ingressar em um curso de graduação é uma etapa de sucesso na vida de um estudante, que muitas vezes chega a demorar algum tempo se dedicando para conseguir a aprovação no processo seletivo para ingresso na universidade.

$\mathrm{O}$ contexto acadêmico passa a ser um novo ambiente para o aluno. Esse ambiente já era idealizado de alguma forma por ele podendo, a realidade encontrada, trazer fatores que motivam a permanência ou não no curso. As técnicas didáticas adotadas pelas Instituições de Ensino Superior (IES) devem manter os estudantes motivados a atingir os objetivos das disciplinas (MAZZIONI, 2013). Diante desse contexto, a pesquisa tem a seguinte problemática: quais os interesses motivacionais dos acadêmicos de Ciências Contábeis da Universidade Estadual do Paraná (UNESPAR) de Campo Mourão?

Esse estudo tem como objetivo analisar os interesses motivacionais dos acadêmicos de Ciências Contábeis de uma universidade pública sob a perspectiva da Teoria da Autodeterminação.

A motivação é o caminho para um bom aprendizado. $O$ acadêmico motivado desenvolve as tarefas de modo mais eficaz, além de tornar a aprendizagem lúdica e prazerosa, e de criar um ambiente mais agradável e propício para aprendizagem (OLIVEIRA, 2017). Para Ramos (2013), no processo de ensino aprendizagem, a motivação representa a realização de um objetivo próprio e futuramente a realização de outros objetivos, em que um acadêmico motivado transforma o conhecimento adquirido em incentivos para posteriores aprendizagens.

O estudo da motivação dos acadêmicos pode contribuir com a gestão psicopedagógica de uma instituição, aprimorando a aprendizagem e o aumento de rendimento escolar dos acadêmicos (LOZANO et al., 2009). Clayton, Blumberg e Auld (2010) associam positivamente motivação e aprendizagem, e destacam a importância em se compreender que a motivação é o caminho para a aprendizagem. De acordo com Silva, Mascarenhas, Medeiros e Sousa (2014), cada instituição e cada acadêmico apresentam suas peculiaridades. Desta forma é importante para a instituição a realização de constantes pesquisas para acompanhar a motivação geral dos acadêmicos, a fim de que estes concluam os estudos.

A realização desse estudo se justifica a fim de compreender as características de motivação dos estudantes, como os tipos e níveis de motivação, segundo a Teoria da Autodeterminação. Com isso, espera-se auxiliar o planejamento de cursos e aulas, já que a motivação é um dos componentes essenciais para a aprendizagem (Silva et al., 2014). Nesse sentido, é necessário o desenvolvimento de estudos que investiguem a motivação dos acadêmicos em relação a sua formação profissional. Conhecer as características da motivação dos acadêmicos pode contribuir com a literatura da motivação no ensino superior, além de trazer implicações para estudantes, professores e coordenação dos cursos, orientando na elaboração de estratégias a fim de tornar seu ambiente acadêmico mais atrativo, reduzindo o número de evasão e aumentando a qualidade da aprendizagem 


\section{REFERENCIAL TEÓRICO}

\subsection{Motivação acadêmica}

A motivação é a força motriz interna nas pessoas e é o que as fazem agir. Por meio de uma tensão gerada por uma necessidade, essa força aparece, e por consequência, as pessoas são direcionadas a tomar uma ação como resposta que se julga apropriada, para à situação (SCHIFFMAN; KANUK, 2000). É a "arte" de estimular o interesse de uma pessoa para um assunto, um trabalho ou um projeto, de modo que constantemente se sintam desafiados para continuar atento, observante, comprometido e preocupado (KAPPA; NITSCKE; SCHAPPER, 1997).

Para Andrade (2012), a motivação é a força interior do indivíduo, a qual é responsável pelo nível de direção e persistência do esforço despendido na realização de um trabalho. Tem relação a fatores de ordem psicológicos, fisiológicos, morais, intelectuais e emocionais que impelem o indivíduo em direção de seus objetivos. Para toda ação humana existe um impulso, um desejo, uma necessidade. Não é casual, aleatória, mas existem motivos por trás que designam um comportamento. A Teoria da autodeterminação (SDT Self-Determination Theory) é uma teoria baseada na motivação humana, desenvolvimento e bem-estar, que não se concentra apenas na quantidade de motivação, mas sim, nos diferentes tipos: motivação Intrínseca e motivação extrínseca. Essa teoria mostrou-se ser adequada ao explicar as diferenças entre estratégias de aprendizagem, desempenho e tenacidade dos estudantes (RYAN; DECI, 2000).

A motivação intrínseca configura-se como melhor fenômeno de potencial da natureza humana, sendo tida como base para o crescimento, coesão social e integridade psicológica (DECl; RYAN, 2000). Buscar novidade, desafios, para conhecer as próprias capacidades é quando o indivíduo se envolve com alguma atividade por conta própria, por estar interessando, ou de alguma forma satisfeito. Há indicadores de que a motivação intrínseca faz com que os alunos se sintam engajados a realizarem as tarefas, motivados a vencer desafios, e que demonstram orgulho acerca dos resultados oriundos de seus esforços. Nesse sentindo, um aluno motivado intrinsicamente é aquele que realiza atividade por meio de metas estipuladas por ele mesmo, esse tipo de motivação independe do ambiente externo (WECHSLER, 2006).

A motivação extrínseca no ambiente escolar acontece quando os estudantes direcionam suas atividades para um fim extrínseco, ou seja, acreditam que o envolvimento com atividade trará resultados almejados, como elogios, notas altas ou deixará de ser punido. Nesse tipo de motivação existe pouca persistência, pois quando retirado a consequência a motivação desaparece. A falta de esforço pode ter origem em razões extrínsecas como, por exemplo, evitar punições ou obter recompensas, nem sempre relacionadas com as atividades (DECl; RYAN, 2000). Um aluno quando está extrinsecamente motivado realiza uma atividade por estar interessado em obter recompensas externas ou sociais, como: obter reconhecimento, demonstrar para outras pessoas competência, ou seja, receber algum tipo de valorização externa (WECHSLER, 2006).

Já a desmotivação ocorre quando a pessoa não tem nenhuma razão, intrínseca ou extrínseca, para realizar uma determinada atividade, podendo ocorrer o abandono da atividade, ou seja, é a ausência de motivação (CARMO; MIRANDA; LEAL, 2012).

Ingressar em uma universidade é algo idealizado pelo acadêmico. Quando este entra em uma universidade têm-se expectativas com o curso, apesar do medo, das dúvidas e das inseguranças que muitas vezes ainda o atinge. Para Bardagi (2007), um estudante irá passar por quatro fases ao ingressar em um curso universitário. A primeira fase é de entusiasmo, quando o aluno tem a aprovação no processo seletivo, ingresso no curso superior, gerando expectativa com o início da formação. A segunda fase é caracterizada pela decepção, insatisfação com o curso, com a instituição, com os professores, e com a sua aprendizagem, e ainda inclui preocupações de uma possível troca de curso. A terceira fase é a reconquista, quando o estudante demonstra um maior interesse na continuidade do curso, sendo que a dedicação nas atividades acadêmicas seria fundamental para o comprometimento com seus estudos. E, por fim, a quarta fase é a expectativa com a formatura, caracterizada pela proximidade do término do curso, a qual gera expectativas quanto a atuação profissional.

Nesse sentido, a universidade deve buscar por estratégias motivacionais com o intuito de receber os novos alunos e os mantê-los ao longo da graduação. Adiciona-se que a motivação é um fator determinante no processo educacional no que diz respeito a qualidade do ensino e da aprendizagem, pois afeta positivamente a maneira como o estudante pensa e se desenvolve. A falta dela leva o estudante a um baixo desempenho durante o período de graduação (OLIVEIRA, 2017).

Valente (2001, p. 71) explica que "motivar ou produzir motivos significa predispor a pessoa para a aprendizagem". Segundo o autor, o acadêmico está motivado quando sente que está disposto a buscar mais conhecimento e a dar continuidade ao seu processo de aprendizagem. Alunos motivados assumem responsabilidade de forma a direcionar suas ações para obter mais conhecimento, buscando assim, o sucesso ao longe de seu caminho acadêmico (CARMO; CARMO, 2014). Ele procurará desenvolver 
habilidade e estratégias para dominar e compreender os novos conteúdos (GUIMARÃES; BORUCHOVITCH, 2004).

Acadêmicos do ensino superior estão enfrentando novos desafios que muitas vezes 'abalam' a motivação de continuar no curso. São desafios associados a dúvidas com relação ao curso escolhido e o que pretendem fazer futuramente com a profissão (GIL et al., 2012). Sendo assim, a motivação é um fator fundamental no processo de aprendizagem e sua ausência pode gerar uma perda de qualidade nesse aspecto (PILETTI, 1997). De acordo com Silva et al. (2014), quando o acadêmico apresenta motivação, ele tem melhores possibilidades de crescimento e sucesso na profissão.

Existe diferença entre desejo de saber e decisão de aprender. A última exige tempo e esforço, os quais dependem da motivação. A falta dessa pode causar sentimentos de angústia, fracasso e frustação (GIL et al., 2012). Outro problema que a desmotivação pode causar é a evasão do curso superior. Segundo Cislaghi (2008), os motivos mais recorrentes para explicar a evasão nas IES nacionais tem relação com o desempenho insatisfatório, com a didática pedagógica ruim, com a sensação de dificuldade de interagir no meio acadêmico, com os materiais do curso não condizentes com o mercado de trabalho, com a falta de estrutura e problemas em responder as demandas do curso, com os interesses pessoais, com as características institucionais e com os diversos motivos pessoais. É um problema a ser considerado, pois além do acadêmico ficar frustrado, perder tempo e dinheiro, a sociedade sofre diretamente quando ocorre a evasão, pois assim, estaria perdendo uma oportunidade de contar com mais um profissional qualificado (CUNHA; NASCIMENTO; DURSO, 2016).

Deve ser ressaltada a importância da motivação para os processos de aprendizagem. No âmbito universitário deve-se buscar além de transmitir conteúdos agregá-los em um espaço que motive seus acadêmicos, os instiguem a superarem desafios e a concluírem etapas necessárias para sua formação. $O$ acadêmico motivado é capaz de estabelecer uma relação de aprendizagem mais eficaz do que aquele que não possui motivação em aprender (OLIVEIRA, 2017).

\subsection{Estudos Anteriores}

A motivação acadêmica e o desempenho acadêmico vem sendo estudado por muitos autores. Amaro (2014) verificou a influência de fatores contingenciais no desempenho acadêmico dos discentes do curso de Ciências Contábeis de Instituições Federais de Educação Superior. Os resultados demonstram que, dos fatores externos, as variáveis: nível de instrução do pai, renda familiar e horas de estudo semanais extraclasse influenciaram no desempenho acadêmico. Já no ambiente institucional, os construtos: ambiente interno, estratégia do projeto pedagógico e sistema técnico do curso mostraram-se influenciadores do desempenho acadêmico dos discentes.

A atuação dos professores exerce influência na motivação e aprendizagem do aluno. A forma de relacionamento com os acadêmicos pode apresentar impactos significativos sobre a motivação intrínseca e extrínseca que estes demostram em sala de aula (CARMO; MIRANDA; LEAL, 2012). Nossa (1999) descreve os professores como principais agentes de mudança no ensino superior, de que não adianta ter muitos recursos financeiros, se a matéria não é ensinada com dedicação e compromisso pelo corpo docente. Ainda o autor, descreve que a mudança na qualidade do ensino, depende das IES capacitar bons profissionais.

Souki e Pereira (2004) realizaram um estudo com o objetivo de identificar a motivação, a satisfação e o comprometimento dos discentes de Administração com a faculdade e com o curso. Os autores verificaram que os fatores: professores, disciplinas, infraestrutura para estudos, horários de aulas e de atendimento, ambiente de trabalho, organização administrativa da faculdade estão positivamente relacionados com os constructos estudados.

Silva e Machado (2005) em um estudo no qual pretendiam avaliar os motivos que levaram o discente em Administração a escolher este curso, verificaram por meio dos resultados da pesquisa, que um dos principais motivos é a formação para exercer no futuro a atividade profissional e poder ter garantia de emprego.

A pesquisa de Falcão e Rosa (2008) identificou que nas universidades públicas os acadêmicos apresentam um aspecto crescente de motivação, na medida em que vão progredindo no curso. Já os acadêmicos de instituições particulares, entram mais motivados e, com o passar do tempo, essa motivação vai decrescendo.

Oliveira et al., (2008) avaliaram a motivação em estudantes de Ciências Contábeis da Universidade Estadual de Montes Claros. Os dados foram coletados em uma amostra de 110 estudantes do curso. Os resultados demostram que as motivações intrínsecas e extrínsecas são fatores que são levados em consideração pela maioria dos estudantes, os principais são: "contribuição do curso para sua formação", "ingresso no mercado de trabalho", "competência profissional", "preciso do diploma", "obter emprego de prestígio", "a fim de ter uma boa remuneração no futuro". E ainda destaca que houve um alto índice para a 
resposta "nenhuma correspondência" à desmotivação.

Leal, Miranda e Carmo (2013) avaliaram a motivação dos estudantes de Ciências Contábeis à luz da Teoria da Autodeterminação. Os dados foram coletados em uma amostra de 259 estudantes do curso. Os resultados apontaram que existe uma motivação bem diversificada para a aprendizagem. As comparações revelaram, por um lado, estudantes preocupados apenas com a obtenção do diploma ou interessados em comparecer às aulas para garantir frequência, por outro lado, estudantes preocupados em aprofundar o nível de conhecimentos ou em atingir uma fundamentação adequada para o desempenho de sua futura atuação.

Ahmad, Ismail e Anantharaman (2015) estudaram as intenções dos estudantes de contabilidade em seguir suas carreiras como contadores na Malásia. Os dados foram coletados por meio de uma pesquisa de questionário envolvendo estudantes de graduação em contabilidade. Os principais achados ressaltam que o interesse intrínseco é um preditor significativo de intenções de carreira. Ou seja, os resultados do estudo sugerem que o foco exclusivo em recompensas extrínsecas não é suficiente para garantir o compromisso com a profissão.

Deci e Ryan (2016) usaram a teoria da autodeterminação e argumentam que o apoio à autonomia de professores e alunos tem vantagens substanciais em termos de resultados educacionais em relação às estratégias de controle. Os resultados mostram que a motivação autônoma tende a florescer em situações em que as pessoas experimentam a satisfação de suas três necessidades psicológicas básicas, as necessidades de competência, relacionamento e autonomia. Os autores afirmam que os professores podem apoiar a satisfação das necessidades psicológicas básicas de seus alunos, especialmente quando os próprios professores são apoiados de maneira semelhante.

Everaert, Opdecam e Maussen (2017) investigam as relações entre aprendizagem, motivação, tempo gasto estudando e desempenho acadêmico. O estudo foi aplicado em um curso de graduação de contabilidade do primeiro ano. Os resultados mostram que alta motivação intrínseca e motivação extrínseca têm uma influência positiva significativa na aprendizagem profunda. E ainda, o aprendizado profundo influencia em um desempenho acadêmico mais alto, já a aprendizagem superficial leva a um menor desempenho acadêmico.

$\mathrm{Ng}$ et al (2017) estudaram a preferência dos estudantes de contabilidade em relação à carreira e a motivação intrínseca ou extrínseca. Foi realizado um levantamento em 306 estudantes de contabilidade de uma universidade privada na Malásia. Os achados sugerem que os estudantes são mais influenciados pela motivação intrínseca na seleção de suas carreiras, enquanto a motivação extrínseca tem menos probabilidade de influenciar as escolhas de carreira dos estudantes de graduação em contabilidade.

Percebe-se que a motivação no âmbito educacional tem sido objeto de estudo devido sua importância atribuída nesse contexto. Motivar alunos e professores pode ser um passo largo para melhorar a educação, desde o nível básico até o nível superior.

\section{PROCEDIMENTOS METODOLÓGICOS}

O estudo caracteriza-se como descritivo, quantitativo e foi operacionalizado por meio de uma survey. A colega de dados deu-se por meio de questionário que foram aplicados no mês de outubro de 2017, sendo apenas em dias com mais alunos em sala de aula. O questionário aplicado na pesquisa foi estruturado e adaptado das pesquisas de Almeida (2012), Cunha, Nascimento e Durso (2016) e Lacerda, Reis e Santos (2008). Composto por questões de identificação e socioeconômicas e perguntas em escalas de 0 a 10 , solicitando que o respondente dê uma nota sendo 0 para discordo plenemente até 10 para concordo plenamente.

Para analisar as médias dos fatores investigados, utilizou-se o seguinte critério: média entre $<0-2,5$ $>0$ fator não teve relevância, $>2,5-5>0$ fator teve baixa relevância, $>5-7,5>0$ fator teve média relevância, $>5-7,5>0$ fator teve média relevância, e $>7,5-10>0$ fator teve alta relevância.

O questionário foi aplicado de forma impressa. Os dados foram exportados para a ferramenta Excel, e em seguida foram analisados utilizando a estatística descritiva, análise fatorial exploratória, correlação de pearson e regressão linear múltipla com auxílio do software Statistical Package for the Social Sciences (IBM SPSS) versão 24.

Em 2017, o curso de Ciências Contábeis da Unespar de Campo Mourão possui matriculados no primeiro ano, segundo ano, terceiro ano e quarto ano respectivamente $85,78,56$ e 72 alunos, totalizando uma população de 291 alunos. A amostra da pesquisa atingiu 168 alunos, sendo não probabilística, tendo um nível de confiança de $95 \%$ e uma margem de erro de $5 \%$.

Foi aplicado um pré-teste em oito alunos do curso de Ciências Contábeis, sendo dois de cada série do curso $\left(1^{\circ}, 2^{\circ}, 3^{\circ}\right.$ e $\left.4^{\circ}\right)$. O tempo médio que os alunos demoraram a responder foi de 7 minutos e não foram identificadas falhas ou inconsistências no questionário. Nesse sentido, o mesmo foi considerado de fácil entendimento por parte dos respondentes. 


\section{RESULTADOS}

\subsection{Análises descritivas}

Para a caracterização da amostra relativa ao curso de Ciências Contábeis da UNESPAR - Campus de Campo Mourão, a apresentação dos resultados das variáveis dos fatores externos e internos é feita em tabelas de frequência e porcentagem. Com relação ao gênero, a amostra é composta por 168 acadêmicos, sendo $97(57,7 \%)$ do gênero feminino, $70(41,7 \%)$ do gênero masculino e 1 omisso $(0,6 \%)$. Observa-se que o número de acadêmicos do gênero feminino é superior ao do gênero masculino, tendo a mesma relação com a pesquisa realizada por Amaro (2014), em que dos 295 acadêmicos da amostra, $167(56,6 \%)$ do gênero feminino e $128(43,4 \%)$ do gênero masculino.

A faixa etária com maior frequência dos acadêmicos foi entre 18 e 24 anos assemelhando-se a pesquisa realizada por Silva et al. (2014) em que 58\% dos acadêmicos tinham entre 18 e 22 anos. Observou-se que a idade que apresentou maior predominância foi 20 anos com 18 respondentes $(10,7 \%)$ e 21 anos com 20 respondentes (11,9\%). $134(79,8 \%)$ dos acadêmicos indicaram ser solteiro, o que condiz com a pesquisa de Amaro (2014), no qual mais de $80 \%$ dos acadêmicos indicaram ser solteiros. Observa-se que $24(14,3 \%)$ casados, $8(4,8 \%)$ união estável, $1(0,6 \%)$ divorciado e $1(0,6 \%)$ omisso.

Em relação a escolaridade da mãe, observou-se que a maior predominância foi ensino fundamental incompleto com 46 respondentes $(27,4 \%)$ e ensino médio incompleto 43 respondentes $(25,6 \%)$. Em relação a escolaridade do pai, observou-se que a maior predominância foi ensino fundamental incompleto com 53 respondentes $(31,5 \%)$ e ensino médio incompleto com 36 respondentes $(21,4 \%)$. Nota-se também que com formação superior completo para mãe obteve 18 respondentes $(10,7 \%)$ e para pai 16 respondentes $(9,5 \%)$. Pode-se observar que poucos pais possuem formação superior, sugerindo ser um fator motivacional para que os acadêmicos estejam realizando o curso.

A variável faixa de renda familiar teve predominância a de 1 a 3 salários-mínimos (de 937,01 a $2.811,00$ ) com 66 respondentes $(39,3 \%$ ) e a de 3 a 6 salários-mínimos (de $2.811,01$ a $5.622,00$ ) com 79 respondentes (47\%). Observa-se que os acadêmicos gastam em média para estudar $\mathrm{R} \$ 224,46$ (duzentos e vinte e quatro reais e quarenta e seis centavos) por mês, sendo estes com transporte, materiais didáticos, livros, entre outros.

Já no que diz respeito onde cursou a maior parte do ensino médio e se realiza outra atividade além de estudar, percebe-se que a maioria dos acadêmicos estudou o ensino médio a maior parte em Instituição Pública, $154(91,7 \%)$ respondentes, condizendo com a pesquisa realizada por Amaro (2014), em que a maioria dos respondentes estudou todo o ensino médio em escola pública. $E$ ainda, a maior parte dos acadêmicos realizam outra atividade além de estudar, com 127 (75,6\%) dos respondentes.

Com relação a distribuição por séries tem-se no $1^{\circ}$ ano com 29 respondentes (17,3\%); $2^{\circ}$ ano com 47 (28\%); $3^{\circ}$ ano com $46(27,4 \%)$; e $4^{\circ}$ no com $44(26,2 \%)$. Quanto à questão município em que reside, observou-se que 67 (39,9\%) respondentes residem no munícipio de Campo Mourão, logo, a maior parte dos acadêmicos se deslocam de municípios próximos para poder estudar.

Quanto à questão se o acadêmico ficou retido em algum ano, notou-se que a maioria não ficou 145 $(86,3 \%)$ respondentes. Neste mesmo âmbito, $113(67,3 \%)$ respondentes disseram não ter disciplina em dependência, $52(31 \%)$ respondentes disseram ter disciplina em dependência, e omissos foram apenas 3 $(1,8 \%)$ respondentes.

Verifica-se na Tabela 1 os dados relativos às relações interpessoais no ambiente acadêmico.

Tabela 1 - Relações interpessoais no ambiente acadêmico

\begin{tabular}{l|c|c|c|c|c|c|c|c|c|c|c|c}
\hline \multirow{2}{*}{ FATORES } & \multicolumn{10}{|c}{ FREQUÊNCIA \%) } \\
\cline { 2 - 14 } & $\mathbf{0}$ & $\mathbf{1}$ & $\mathbf{2}$ & $\mathbf{3}$ & $\mathbf{4}$ & $\mathbf{5}$ & $\mathbf{6}$ & $\mathbf{7}$ & $\mathbf{8}$ & $\mathbf{9}$ & $\mathbf{1 0}$ & MÉD \\
\hline Relação com os colegas & 0 & 0,6 & 0,6 & 0 & 2,4 & 4,8 & 4,2 & 12,5 & 28 & 21,4 & 25,6 & 8,2 \\
\hline Relação com os professores & 0 & 0 & 0,6 & 0 & 0 & 6 & 6 & 23,5 & 34,5 & 17,3 & 12,5 & 7,86 \\
\hline Relação com a coordenação & 1,8 & 2,4 & 1,2 & 5,4 & 2,4 & 19,6 & 11,9 & 13,7 & 19 & 8,9 & 13,7 & 6,65 \\
\hline Relação com a Instituição & 1,2 & 0,6 & 1,2 & 3,6 & 2,4 & 15,5 & 13,1 & 14,3 & 22,6 & 12,5 & 12,5 & 7,02 \\
\hline Relação com a rotina de estudo & 0,6 & 0,6 & 1,8 & 3 & 4,8 & 16,7 & 7,8 & 25 & 22,6 & 8,9 & 8,3 & 6,81 \\
\hline MÉDIA GERAL DOS FATORES & $\mathbf{0 , 7}$ & $\mathbf{0 , 8}$ & $\mathbf{1 , 1}$ & $\mathbf{2 , 4}$ & $\mathbf{2 , 4}$ & $\mathbf{1 2 , 5}$ & $\mathbf{8 , 6}$ & $\mathbf{1 7 , 8}$ & $\mathbf{2 5 , 3}$ & $\mathbf{1 3 , 8}$ & $\mathbf{1 4 , 5}$ & $\mathbf{7 , 3 1}$ \\
\hline
\end{tabular}

"Relação com os colegas" observa-se que as maiores frequências foram no intervalo de 8 a 10, com $75 \%$ dos respondentes. Os dados apontam uma boa relação entre os acadêmicos e que apenas $3,6 \%$ dos respondentes atribuíram notas de 0 a 4 . Este item obteve a maior média na Tabela 1 que foi de 8,2 . A pesquisa realizada por Bardagi e Hutz (2012) apresentou resultado semelhante, $75 \%$ dos entrevistados, 
descreveram ter bons relacionamentos com colegas, e que a amizade ultrapassou as fronteiras da instituição.

Em "Relação com os professores" observou-se que as maiores frequências foram no intervalo de 7 a 8 , com $57,7 \%$ dos respondentes. Os dados sugerem que existe também uma boa relação entre acadêmicos e professores, tendo uma média de 7,86. A atuação dos professores exerce grande influência na motivação e aprendizagem do aluno (CARMO; MIRANDA; LEAL, 2012).

Com relação aos itens "Relação com a coordenação" e "Relação com a Rotina de estudo" a média apresentou uma semelhança sendo de 6,65 e 6,81 respectivamente. Os dados sugerem que a relação com a coordenação e com a rotina de estudo pode ser considerada regular, tendo uma média próxima a 7.

No que diz respeito ao item "Relação com a Instituição" a maior frequência foi a nota 8 com 22,6\% seguido pela nota 5 com 15,5\%. A média foi de 7,02, apontando para uma boa relação entre os acadêmicos e a instituição. Nota-se que a maior média foi 8,2 referente à relação com os colegas e a menor média foi 6,65 com relação a coordenação.

$\mathrm{Na}$ Tabela 2, apresentam-se os dados relativos aos fatores de desmotivação dos acadêmicos.

Tabela 2 - Fatores de desmotivação dos acadêmicos

\begin{tabular}{|c|c|c|c|c|c|c|c|c|c|c|c|c|}
\hline \multirow{2}{*}{ FATORES } & \multicolumn{12}{|c|}{ FREQUÊNCIA (\%) } \\
\hline & 0 & 1 & 2 & 3 & 4 & 5 & 6 & 7 & 8 & 9 & 10 & MÉD \\
\hline Estou perdendo tempo neste curso & 69 & 3,6 & 7,1 & 4,2 & 4,2 & 3 & 1,8 & 2,4 & 0 & 1,8 & 3 & 1,35 \\
\hline Tenho dúvidas sobre continuar & 53,6 & 6 & 4,8 & 7,1 & 3,6 & 5,4 & 3 & 3,6 & 3,6 & 2,4 & 7,1 & 2,42 \\
\hline Eu não sei o que estou fazendo neste curso & 62,5 & 4,8 & 8,9 & 6 & 3 & 2,4 & 1,8 & 4,8 & 2,4 & 1,2 & 2,4 & 1,62 \\
\hline Este curso não faz diferença na minha vida & 77,4 & 4,8 & 4,2 & 3,6 & 0,6 & 3,6 & 1,2 & 1,8 & 2,4 & 0 & 0,6 & 0,89 \\
\hline Gostaria de fazer outro curso & 45,2 & 4,2 & 4,8 & 4,2 & 1,2 & 11,3 & 3 & 6 & 9,5 & 2,4 & 7,7 & 3,24 \\
\hline Faço este porque não encontrei o ideal pra mim & 56,2 & 5,4 & 6,5 & 4,2 & 4,8 & 8,3 & 3 & 2,4 & 5,4 & 0,6 & 3 & 2,05 \\
\hline MÉDIA GERAL DOS FATORES & 60,7 & 4,8 & 6,1 & 4,9 & 2,9 & 5,7 & 2,3 & 3,5 & 3,9 & 1,4 & 4 & 1,93 \\
\hline
\end{tabular}

Os dados da Tabela 2 sugerem que os acadêmicos entrevistados não apresentam relevantes índices de desmotivação. A maior média encontrada foi de 3,24, para o fator "gostaria de fazer outro curso". 0 resultado demonstra que os acadêmicos não possuem perfil de desmotivação, refletindo o resultado evidenciado na Tabela 1, em que se verifica que os acadêmicos possuem boa relação entre os professores, amigos e a instituição.

Nota-se, ainda, na Tabela 2 que a nota 0 obteve as maiores frequências em todos os fatores, sendo a maior com $77,4 \%$ e a menor com 45,2\%. Assemelhando-se com a pesquisa realizada por Oliveira et al. (2008), no qual foi destacado que houve um alto índice para a resposta "nenhuma correspondência" à desmotivação. acadêmicos.

Em adição, na Tabela 3 apresentam-se os dados relativos aos fatores de motivação intrínseca dos

Tabela 3 - Motivação intrínseca dos acadêmicos em relação ao curso

\begin{tabular}{|c|c|c|c|c|c|c|c|c|c|c|c|c|}
\hline \multirow{2}{*}{ FATORES } & \multicolumn{12}{|c|}{ FREQUÊNCIA (\%) } \\
\hline & 0 & 1 & 2 & 3 & 4 & 5 & 6 & 7 & 8 & 9 & 10 & MÉD \\
\hline Para provar pra mim mesmo que sou capaz & 25 & 5,4 & 4,2 & 4,2 & 3,0 & 13,2 & 9,5 & 7,7 & 13,7 & 4,8 & 8,9 & 4,59 \\
\hline Sinto orgulho por estar fazendo este curso & 3,6 & 1,2 & 1,8 & 0 & 2,4 & 8,9 & 7,7 & 9,5 & 16,1 & 19,6 & 28,6 & 7,68 \\
\hline Identifico-me com o curso & 4,2 & 1,2 & 2,4 & 1,8 & 1,2 & 13,1 & 7,7 & 13,7 & 17,3 & 10,7 & 26,2 & 7,25 \\
\hline Quero ter o meu próprio negócio & 35,7 & 0,6 & 7,7 & 2,4 & 1,2 & 10,1 & 3,6 & 7,7 & 11,3 & 3,6 & 14,9 & 4,4 \\
\hline Por ser importante ter curso superior & 7,7 & 1,8 & 1,8 & 1,8 & 1,2 & 5,4 & 8,3 & 4,8 & 14,3 & 4,8 & 47,6 & 7,63 \\
\hline Estou aprendendo assuntos interessantes & 1,8 & 1,2 & 1,2 & 2,4 & 5,4 & 5,4 & 14,9 & 22,6 & 0,6 & 14,9 & 29,2 & 7,95 \\
\hline MÉDIA GERAL DOS FATORES & 13 & 1,9 & 3,2 & 2,1 & 2,4 & 9,4 & 8,6 & 11 & 12,2 & 9,7 & 25,9 & 6,58 \\
\hline
\end{tabular}

Os dados da Tabela 3 sugerem que os acadêmicos são motivados por fatores intrínsecos. Os fatores "Estou aprendendo assuntos interessantes", "Sinto orgulho por estar fazendo este curso", "Por ser importante ter curso superior", "Identifico-me com o curso" são relevantes para os acadêmicos entrevistados. Sendo a nota $10 \mathrm{com}$ a maior frequência em todos esses fatores citados, destacando-se $47,6 \%$ para os acadêmicos que consideram ser importante ter curso superior. Condizendo com a pesquisa realizada por Oliveira et al. (2008), em que os resultados demostraram que fatores de motivação intrínseca são levados em consideração pela maioria dos estudantes. Os fatores "Para provar pra mim mesmo que 
sou capaz" e "Quero ter o meu próprio negócio" não tiveram tanta relevância para os acadêmicos.

Consoante ao exposto, na Tabela 4 apresentam-se os dados relativos aos fatores de motivação extrínseca.

Tabela 4 - Motivação extrínseca dos acadêmicos em relação ao curso

\begin{tabular}{|c|c|c|c|c|c|c|c|c|c|c|c|c|}
\hline \multirow{2}{*}{ FATORES } & \multicolumn{12}{|c|}{ FREQUÊNCIA (\%) } \\
\hline & 0 & 1 & 2 & 3 & 4 & 5 & 6 & 7 & 8 & 9 & 10 & MÉD \\
\hline Faço este curso porque é o que esperam de mim & 45,2 & 3,6 & 6,0 & 4,2 & 3,0 & 12,5 & 8,3 & 3,0 & 6,0 & 2,4 & 5,4 & 2,98 \\
\hline Os amigos são o principal motivo de continuar & 39,9 & 2,4 & 7,1 & 0,3 & 1,8 & 10,7 & 6 & 3,6 & 0,9 & 4,2 & 6,5 & 3,4 \\
\hline Gosto que as pessoas saibam que faço & 7,7 & 1,8 & 1,2 & 5,4 & 1,2 & 14,9 & 6 & 10,1 & 20,8 & 9,5 & 20,8 & 6,71 \\
\hline Faço este curso pelo retorno financeiro & 7,7 & 1,2 & 1,2 & 3,6 & 3,6 & 16,7 & 8,3 & 22,6 & 15,5 & 6 & 13,1 & 6,32 \\
\hline Porque há diversas oportunidades de emprego & 11,3 & 1,2 & 1,2 & 0,6 & 1,2 & 8,3 & 7,7 & 14,9 & 20,2 & 10,1 & 22 & 6,92 \\
\hline Faço este curso porque já trabalho na área & 49,4 & 2,4 & 3 & 3 & 1,8 & 5,4 & 4,8 & 7,1 & 5,4 & 4,8 & 12,5 & 3,42 \\
\hline Professores são bons, as aulas são dinâmicas. & 4,2 & 1,8 & 3,6 & 4,2 & 4,8 & 18,5 & 11,9 & 22 & 14,9 & 7,7 & 6 & 6,1 \\
\hline Faculdade têm bons recursos de aprendizagem & 8,3 & 1,8 & 3 & 3,6 & 6 & 20,2 & 13,7 & 21,4 & 12,5 & 3,6 & 5,4 & 5,65 \\
\hline MÉDIA GERAL DOS FATORES & 21,7 & 2 & 3,3 & 3,1 & 2,9 & 13,4 & 8,3 & 13,1 & 12,0 & 6 & 11,5 & 5,19 \\
\hline
\end{tabular}

Fonte: Dados da pesquisa

Observou-se por meio da Tabela 4 que os itens "Faço este curso porque é o que esperam de mim"; "Os amigos são o principal motivo de continuar o curso" e "Faço este curso porque já trabalho na área" obtiveram médias baixas. Ou seja, sugere-se que as motivações dos respondentes da pesquisa não estão relacionadas ao desejo de pessoas próximas, mas ao status que a profissão pode trazer perante a sociedade. Para confirmar essa sugestão, tem-se o item "Gosto que as pessoas saibam que faço" que a média foi de 6,71 e maior frequência entre nas notas 8 e 10.

No que se refere ao item "Faço este curso pelo retorno financeiro", foi obtido média igual a 6,32 . A maior frequência das notas se deu entre 5 e 7 , indicando que o retorno financeiro é um fator que tem média motivação para a maioria dos acadêmicos que participaram da pesquisa. Assim como os itens: "Professores são bons, as aulas são dinâmicas" e "Faculdade têm bons recursos de aprendizagem" que obtiveram média de 6,1 e 5,65. A maior frequência desses itens se deu também entre as notas 5 e 7 , observando que quanto a estes fatores a maior parte dos respondentes se justificam como regularmente motivados.

O item "Porque há diversas oportunidades de emprego", obteve média de 6,92. A maior frequência das notas nesse item se deu entre 8 e $10(52, \%)$. Sugere-se que as diversas oportunidades do mercado de trabalho da área de Ciências Contábeis é um fator de motivação extrínseco para um considerável número de acadêmicos respondentes. Os resultados da Tabela 4 condizem com a pesquisa realizada por Oliveira et al. (2008), em que os resultados demostraram que fatores de motivação extrínseca são levados em consideração pela maioria dos estudantes. Na Tabela 5, demonstra-se os fatores de auto avaliação dos acadêmicos em relação ao curso.

Tabela 5 - Fatores de auto avaliação dos acadêmicos em relação ao curso

\begin{tabular}{|c|c|c|c|c|c|c|c|c|c|c|c|c|}
\hline \multirow{2}{*}{ FATORES } & \multicolumn{12}{|c|}{ FREQUÊNCIA (\%) } \\
\hline & 0 & 1 & 2 & 3 & 4 & 5 & 6 & 7 & 8 & 9 & 10 & MÉD \\
\hline Pontualidade nas aulas & 3 & 0 & 1,2 & 2,4 & 2,4 & 3 & 7,1 & 16,1 & 20,2 & 17,3 & 26,8 & 7,79 \\
\hline Frequência nas aulas & 0,6 & 0 & 0,6 & 0,6 & 2,4 & 6 & 4,8 & 20,8 & 26,2 & 22 & 15,5 & 7,84 \\
\hline Participação nas aulas & 1,2 & 0 & 1,2 & 0,6 & 4,2 & 12,5 & 7,7 & 22 & 25 & 16,7 & 8,3 & 7,22 \\
\hline Desempenho na resolução de exercícios & 0 & 0,6 & 0,6 & 2,4 & 2,4 & 12,5 & 7,1 & 19 & 26,8 & 19,6 & 8,3 & 7,36 \\
\hline Desempenho nas provas e testes & 1,2 & 0 & 1,2 & 0 & 0,6 & 9,5 & 10,7 & 30,4 & 32,1 & 7,1 & 6,5 & 7,20 \\
\hline MÉDIA GERAL DOS FATORES & 1,2 & 0,1 & 1 & 1,2 & 2,4 & 8,7 & 7,5 & 21,7 & 26,1 & 16,5 & 13,1 & 7,48 \\
\hline
\end{tabular}

Frente a Tabela 5 notou-se que as frequências mais predominantes foram entre as notas 7 e 10, bem como as médias apresentaram pouca variação, sendo a menor com 7,2 e a maior com 7,84. Nota-se que sobre a pontualidade nas aulas, a nota 10 obteve a maior frequência $26,8 \%$. Nota-se também que a nota 8 obteve as maiores frequências para os fatores "Frequência nas aulas", "Participação nas aulas", "Desempenho na resolução de exercícios" e "Desempenho nas provas e testes", com $26,2 \%, 25 \%, 26,8 \%$ e $32,10 \%$ respectivamente.

Ainda sobre a Tabela 5, notou-se com relação a auto avaliação dos acadêmicos, mais especificamente, concatenada ao bom desempenho, em relação ao curso, que o mesmo pode ser associado aos mesmos declararem-se motivados a estudar. Conforme o estudo de Ramos (2013), 
estudantes motivados são participativos e ativos, procuram sempre mais informações, se esforçam e se dedicam para desenvolver melhores estratégias em busca da compreensão e do domínio dos conteúdos.

\subsection{Correlação e regressão linear múltipla}

A fim de conhecer melhor os efeitos entre as variáveis de motivação intrínseca, motivação extrínseca, desmotivação e auto avaliação do desempenho foram realizadas correlações e regressões lineares múltiplas. Primeiramente, foi reduzido a um único fator as variáveis da auto avaliação do desempenho por meio da análise fatorial exploratória (AFE). O índice Kaiser-Meyer-Olkin foi de 0,628, sendo que valores acima de 0,6 são considerados adequados, e o valor do teste de Bartlett foi significativo, mostrando ser apropriado a realização da AFE. Em seguida, realizou-se a correlação entre as variáveis, os achados apontam uma correlação baixa negativa e significativa entre as variáveis "Eu realmente sinto que estou perdendo meu tempo neste curso" $(-0,259)$, "Eu já tive boas razões para cursar este curso, mas, agora tenho dúvidas sobre continuar" $(-0,177)$, "Eu não sei, eu não entendo o que estou fazendo neste curso" ($0,273)$ e "Eu não vejo que faz diferença na minha vida estar cursando este curso" $(-0,159)$ na auto avaliação do desempenho. Esses resultados apontam que a quanto maior a desmotivação de um estudante, menor será sua auto avaliação de desempenho.

No que se refere a motivação intrínseca, os dados revelam uma baixa correlação positiva e significativa entre as variáveis "Faço este curso para provar a mim mesmo que sou capaz" $(0,195)$, "Me sinto orgulhoso por estar em um fazendo este curso" $(0,300)$, "Eu realmente me identifiquei com o curso" $(0,307)$ e "Faço este curso porque acredito que seja importante ter um ensino superior" $(0,142)$ na auto avaliação do desempenho dos estudantes. A partir disso, pode-se afirmar que a motivação intrínseca está correlacionada a auto avaliação dos discentes.

Já com relação a motivação extrínseca, as variáveis que apresentaram correlação positiva e significativa com a auto avaliação de desempenho dos estudantes foram "Gosto que as pessoas saibam que faço este curso" $(0,248)$, "Faço este curso pelo retorno financeiro" $(0,258)$, "Faço este curso porque os professores são muito bons, as aulas são dinâmicas" $(0,264)$ e "Faço este curso porque a universidade oferece ótimos recursos de aprendizagem" $(0,285)$.

Com o objetivo de verificar a influência das variáveis de desmotivação, motivação intrínseca e extrínseca na auto avaliação de desempenho dos estudantes foram realizadas regressões lineares múltiplas. A Tabela 6 apresenta os resultados para influência da desmotivação na auto avaliação do desempenho.

Tabela 6 - Efeitos das variáveis de desmotivação na auto avaliação do desempenho de estudantes

\begin{tabular}{|c|c|c|c|c|c|}
\hline \multirow[t]{2}{*}{ Regressão Linear Múltipla $R^{2}=0,144$} & \multicolumn{2}{|c|}{ Coeficientes } & \multirow{2}{*}{$\begin{array}{c}\begin{array}{c}\text { Coeficientes } \\
\text { padronizados }\end{array} \\
\text { Beta }\end{array}$} & \multirow{2}{*}{$\mathbf{t}$} & \multirow{2}{*}{ Sig. } \\
\hline & B & Std. Error & & & \\
\hline (Constant) & ,025 & 107 & & ,237 & ,813 \\
\hline Eu realmente sinto que estou perdendo meu tempo neste curso &,- 076 & 041 &,- 191 & $-1,845$ & 067 \\
\hline $\begin{array}{l}\text { Eu já tive boas razões para cursar este curso, mas, agora tenho } \\
\text { dúvidas sobre continuar }\end{array}$ & ,030 & 033 &, 100 & ,908 & ,365 \\
\hline $\begin{array}{l}\text { Eu não sei, eu não entendo o que estou fazendo neste } \\
\text { curso }\end{array}$ &,- 094 & ,041 &,- 257 & $-2,280$ & ,024 \\
\hline $\begin{array}{l}\text { Eu não vejo que faz diferença na minha vida estar cursando } \\
\text { este curso }\end{array}$ & ,002 & ,042 & ,005 & ,055 & ,956 \\
\hline $\begin{array}{l}\text { Faço este curso porque foi neste que passei, mas gostaria } \\
\text { de fazer outro curso }\end{array}$ & ,078 & ,025 & 284 & 3,137 & ,002 \\
\hline $\begin{array}{l}\text { Faço este curso porque ainda não encontrei o curso ideal para } \\
\text { mim }\end{array}$ &,- 043 & ,031 &,- 128 & $-1,374$ & 171 \\
\hline
\end{tabular}

Fonte: Dados da pesquisa, 2017

Percebe-se na Tabela 6 que a variável "Eu não sei, eu não entendo o que estou fazendo neste curso" possui influência significativa e negativa na auto avaliação de desempenho dos estudantes. Já a variável "Faço este curso porque foi neste que passei, mas gostaria de fazer outro curso" apontou uma influência positiva e significativa, ou seja, o fato de um estudante almejar realizar outro curso não afeta de forma negativa no desempenho deste curso que está realizando. A Tabela 7 mostra os resultados a influência da motivação intrínseca na auto avaliação de desempenho dos estudantes investigados. 
Tabela 7 - Efeitos das variáveis de motivação intrínseca na auto avaliação de desempenho de estudantes

\begin{tabular}{|c|c|c|c|c|c|}
\hline \multirow[t]{2}{*}{ Regressão Linear Múltipla $\mathbf{R}^{2}=0,147$} & \multicolumn{2}{|c|}{ Coeficientes } & \multirow{2}{*}{$\begin{array}{c}\begin{array}{c}\text { Coeficientes } \\
\text { padronizados }\end{array} \\
\text { Beta }\end{array}$} & \multirow[b]{2}{*}{ t } & \multirow[b]{2}{*}{ Sig. } \\
\hline & B & Std. Error & & & \\
\hline (Constant) & $-1,134$ & ,273 & & $-4,158$ & 000 \\
\hline Faço este curso para provar a mim mesmo que sou capaz & ,048 & ,022 & , 170 & 2,229 & ,027 \\
\hline Me sinto orgulhoso por estar em um fazendo este curso & ,029 & ,043 & ,074 & ,674 & ,501 \\
\hline Eu realmente me identifiquei com o curso & ,099 & ,039 & ,264 & 2,516 & ,013 \\
\hline Faço este curso porque quero ter meu próprio negócio &,- 026 & 019 &,- 106 & $-1,367$ & ,173 \\
\hline $\begin{array}{l}\text { Faço este curso porque acredito que seja importante ter um } \\
\text { ensino superior }\end{array}$ & ,012, & 025, & ,040, & 490 & ,625 \\
\hline
\end{tabular}

Fonte: Dados da pesquisa, 2017

Verifica-se que as variáveis da motivação intrínseca como "Faço este curso para provar a mim mesmo que sou capaz" e "Eu realmente me identifiquei com o curso" podem afetar positivamente na auto avaliação do desempenho dos estudantes. Já as outras variáveis não apresentaram resultados significativos. A seguir, a Tabela 8 evidencia os efeitos da motivação extrínseca na auto avaliação de desempenho dos estudantes.

Tabela 8 - Efeitos das variáveis de motivação extrínseca na auto avaliação de desempenho dos estudantes

\begin{tabular}{|c|c|c|c|c|c|}
\hline \multirow[t]{2}{*}{ Regressão Linear Múltipla $\mathbf{R}^{2}=0,189$} & \multicolumn{2}{|c|}{ Coeficientes } & \multirow{2}{*}{\begin{tabular}{|c|}
$\begin{array}{c}\text { Coeficientes } \\
\text { padronizados }\end{array}$ \\
Beta
\end{tabular}} & \multirow[t]{2}{*}{$\mathbf{t}$} & \multirow{2}{*}{ Sig. } \\
\hline & B & Std. Error & & & \\
\hline (Constant) & $-1,021$ & 278 & & $-3,680$ & 000 \\
\hline Meus amigos são meu principal motivo de continuar o curso &,- 042 & 023 &,- 146 & $-1,845$ & ,067 \\
\hline Faço este curso porque é isso que esperam de mim & 001 & ,023 & ,002 & ,022 & ,983 \\
\hline Gosto que as pessoas saibam que faço este curso & 044 & ,027 & ,131 & 1,631 & ,105 \\
\hline Faço este curso pelo retorno financeiro & ,093 & ,031 & ,254 & 2,969 &, 003 \\
\hline Faço este curso porque já trabalho na área &,- 009 & ,019 &,- 034 &,- 450 & ,653 \\
\hline Faço este curso porque há diversas oportunidades de emprego &,- 045 & ,024 &,- 148 & $-1,870$ & ,063 \\
\hline $\begin{array}{l}\text { Faço este curso porque os professores são muito bons, as aulas } \\
\text { são dinâmicas }\end{array}$ & 064 & ,045 & ,155 & 1,411 &, 160 \\
\hline $\begin{array}{l}\text { Faço este curso porque a universidade oferece ótimos recursos } \\
\text { de aprendizagem }\end{array}$ & ,043 & ,044 &, 110 & ,981 & ,328 \\
\hline
\end{tabular}

Fonte: Dados da pesquisa, 2017

Dentre todas as variáveis de motivação extrínseca analisadas apenas "Faço este curso pelo retorno financeiro" apresentou resultado significativo, indicando que o anseio por retorno financeiro pode influenciar positivamente na auto avaliação do desempenho.

\section{CONSIDERAÇÕES FINAIS}

O objetivo da pesquisa foi investigar a motivação dos acadêmicos de Ciências Contábeis de uma universidade pública. Quanto ao perfil da amostra da pesquisa, obteve-se predominância do sexo feminino. A maior parte dos respondentes eram solteiros, e tinham entre 18 e 22 anos. A faixa de renda que teve maior frequência foi a 3 a 6 salários-mínimos. A maior parte dos acadêmicos cursou todo ensino médio em escola pública e atualmente realiza outra atividade além de estudar, como trabalho ou estágio. A maioria dos respondentes reside em municípios próximos a Campo Mourão, e gastam em média $R \$ 224,46$ por mês, incluindo deslocamento, alimentação, entre outros gastos. Quanto a escolaridade dos pais dos acadêmicos da amostra, a maioria não completou o ensino fundamental. Sobre dependências em outras disciplinas e retenções a maior parte dos respondentes disserem que não possuem.

Observou-se que a relação dos acadêmicos com os colegas e professores foram de altas médias, indicando uma boa relação, o que é dado positivo para a instituição, pois a criação de vínculos com colegas exerce um forte impacto sobre o envolvimento acadêmico, melhorando, assim, a motivação para executar tarefas (FIOR, 2008) e a atuação dos professores exerce influência significativa na motivação e aprendizagem do aluno (CARMO; MIRANDA; LEAL, 2012).

No que se refere aos fatores de desmotivação dos acadêmicos, as médias obtidas com as respostas da amostra foram baixas, indicando que não houve um fator que indicasse que há um alto índice de desmotivação para os acadêmicos da amostra. Esse resultado corrobora com os achados de Oliveira et al. (2008), em que foi destacado que houve um alto índice para a resposta "nenhuma correspondência" à desmotivação. 
Nota-se que os fatores intrínsecos são os que mais motivam os acadêmicos que participaram da pesquisa, destacando o orgulho de cursar Ciências Contábeis, a identificação do acadêmico com o curso, a importância de se ter um curso superior e a aprendizagem de assuntos interessantes, o que corrobora com os estudos de Everaert, Opdecam e Maussen (2017) e $\mathrm{Ng}$ et al. (2017). Quanto aos fatores extrínsecos os que mais motivam os respondentes foram, respectivamente, as oportunidades do mercado de trabalho, o retorno financeiro da profissão e "Gosto que as pessoas saibam que faço", indicando que o status que a profissão tem perante a sociedade é um fator motivacional. Menciona-se, ainda, que o resultado da auto avaliação dos acadêmicos é reflexo da motivação dos mesmos. Altas médias foram obtidas, indicando que por serem acadêmicos motivados a pontualidade, frequência e participação nas aulas é boa, assim como, se tem bom desempenho em resolução de exercícios, provas e testes.

Os resultados apontam que a quanto maior a desmotivação de um estudante, menor será sua auto avaliação de desempenho. E ainda, o fato de se identificar com o curso, a necessidade de provar a si mesmo sua capacidade e o anseio de retorno financeiro influenciam positivamente na auto avaliação de desempenho dos estudantes de contabilidade investigados.

Conclui-se que grande parte dos acadêmicos que participaram da pesquisa se encontram motivados com o curso, devido a fatores intrínsecos e extrínsecos, e, também, devido a boa relação interpessoal que possuem com colegas, professores e instituição. Isso reflete nas atribuições de notas altas em suas auto avaliação. É um resultado positivo para o curso de Ciências Contábeis da UNESPAR-CM, pois de acordo com Silva et al. (2014), quando o acadêmico apresenta motivação, ele tem melhores possibilidades de crescimento e sucesso na profissão. Portanto, cabe a universidade oferecer recursos que cada vez mais motivem seus acadêmicos a terem o anseio de aprender para que assim estes saiam da universidade como profissionais qualificados, desempenhando um bom papel perante a sociedade.

Esse estudo traz contribuições teóricas e práticas, uma vez que adota a teoria da autodeterminação para compreender melhor os níveis e tipos de motivação dos estudantes de contabilidade e seus efeitos na auto avaliação do desempenho. Não é possível generalizar os resultados devido às limitações da pesquisa, em virtude da amostra ser restrita a uma única universidade, além de que outras variáveis poderiam ser investigadas. No entanto, tais limitações podem servir como recomendações para futuras pesquisas, ou seja, expandir a amostra e o estudo para outras instituições e, também, investigar outras possíveis variáveis que indicam motivação e/ou desmotivação dos acadêmicos.

\section{REFERÊNCIAS}

AHMAD, Z.; ISMAIL, H.; ANANTHARAMAN, R. N. To be or not to be: an investigation of accounting students' career intentions. Education+Training, v. 57, n. 3, p. 360-376, 2015

ALMEIDA. D. A motivação do aluno no ensino superior: um estudo exploratório. 2012. 147 f. Dissertação de Mestrado em Educação, Universidade Estadual de Londrina, Centro de Educação, Comunicação e Artes, Programa de Pós-Graduação em Educação, Londrina, 2012.

AMARO, H. D. Influência de fatores contingenciais no desempenho acadêmico de discentes do curso de ciências contábeis de IFES. Dissertação de Mestrado em Contabilidade, Universidade Federal do Paraná, Curitiba, 2014.

ANDRADE, J. L. Educação Superior: abordagem de motivação e necessidade. 2012. Disponível em: <http://www.administradores.com.br/artigos/economia-e-financas/educacao-superior-uma-abordagem-de-motivacao-enecessidade/66246/>. Acesso em 11 dez. 2017.

BARDAGI, M. P. Evasão e Comportamento Vocacional de Universitários: estudo sobre o desenvolvimento de carreira na graduação. Tese de Doutorado em Psicologia, Programa de Pós-Graduação em Psicologia do Instituto de Psicologia da Universidade Federal do Rio Grande do Sul, 2007.

BARDAGI, M. P.; HUTZ, C. S. Rotina acadêmica e relação com colegas e professores: impacto na evasão universitária. Psico, v. 43, n. 2, p. 5, 2012.

CARMO, C. R. S.; CARMO, R. de O. S. Motivação para aprendizagem no ensino superior: um estudo envolvendo o estágio curricular, alunos da modalidade presencial e alunos do curso a distância. Cadernos da FUCAMP, v. 13, n. 18, 2014.

CARMO, C. R. S.; MIRANDA, G. J.; LEAL, E. A. Motivação discente para a aprendizagem das disciplinas do curso de Ciências Contábeis. Registro Contábil, v. 3, n. 3, p. 123-143, 2012.

CISLAGHI, R. Um modelo de sistema de gestão do conhecimento em um framework para a promoção da permanência discente no ensino de graduação. 2008. Tese de Doutorado em Engenharia e Gestão do Conhecimento, Programa de Pós-Graduação em Engenharia e Gestão do Conhecimento da Universidade Federal de Santa Catarina, 2008.

CLAYTON, K.; BLUMBERG, F.; AULD, D. P. The relationship between motivation, learning strategies and choice of environment whether traditional or including an online component. British Journal of Educational Technology, v. 41, n. 3, p. 349-364, 2010. 
CUNHA, J. V. A.; NASCIMENTO, E. M.; OLIVEIRA DURSO, S. Razões e influências para a evasão universitária: um estudo com estudantes ingressantes nos cursos de Ciências Contábeis de instituições públicas federais da Região Sudeste. Advances in Scientific and Applied Accounting, v. 9, n. 2, p. 141-161, 2016.

DECI, E. L.; RYAN, R. M. The "what" and "why" of goal pursuits: Human needs and the self-determination of behavior. Psychological inquiry, v. 11, n. 4, p. 227-268, 2000.

DECI, E. L.; RYAN, R. M. Optimizing students' motivation in the era of testing and pressure: A self-determination theory perspective. Building autonomous learners. Springer, Singapore, p. 9-29, 2016.

DIAS, L. N. da S.; MOREIRA, A. C. S. As perspectivas da profissão contábil para os formandos em Ciências Contábeis do Instituto de Estudos Superiores da Amazônia-IESAM. In: CONGRESSO BRASILEIRO DE CONTABILIDADE. 2008.

EVERAERT, P.; OPDECAM, E.; MAUSSEN, S. The relationship between motivation, learning approaches, academic performance and time spent. Accounting Education, v. 26, n. 1, p. 78-107, 2017.

FALCÃO, D. F.; ROSA, V da. Um estudo sobre a motivação dos universitários do curso de administração: uma contribuição para gestão acadêmica no âmbito público e privado. Anais do Encontro da Associação Nacional de Pós-graduação e Pesquisa em Administração, Rio de Janeiro, RJ, Brasil, v. 32, 2008.

FIOR, C. A. Interações dos universitários com os pares e envolvimento acadêmico: análise através da modelagem de equações estruturais. 2008. Tese de Doutorado em Educação, Universidade Estadual de Campinas, Campinas, 2008.

GIL, E. S. et al. Estratégias de ensino e motivação de estudantes no ensino superior. Vita et Sanitas, v. 6, n. 1, p. 5781, 2012.

RUFINI, S. É. G.; BORUCHOVITCH, E. O Estilo motivacional do professor e a motivação intrínseca dos estudantes: uma perspectiva da teoria da autodeterminação. Psicologia: Reflexão e Crítica, v. 17, n. 2, p. . 143-150, 2004.

LACERDA, J. R.; REIS, S. M.; SANTOS, N. A. Os fatores extrínsecos e intrínsecos que motivam os alunos na escolha e na permanência no curso de ciências contábeis: um estudo da percepção dos discentes numa universidade pública. Enfoque: Reflexão Contábil, v. 27, n. 1, p. 67-81, 2008.

LEAL, E. A.; MIRANDA, G. J.; CARMO, C. R. S. Teoria da autodeterminação: uma análise da motivação dos estudantes do curso de ciências contábeis. Revista Contabilidade \& Finanças, v. 24, n. 62, p. 162-173, 2013.

LOZANO, A. B. et al. Motivação académica e atribuições causais: A escala QEAP48 numa amostra de alunos universitários de Rondônia e Humaitá (Amazónia, Brasil). In: Actas do X Congresso internacional Galeco-Português de Psicopedagogia. Braga: Universidade do Minho. 2009. p. 4497-4508.

MAZZIONI, S. As estratégias utilizadas no processo de ensino-aprendizagem: concepções de alunos e professores de ciências contábeis. Revista Eletrônica de Administração e Turismo-ReAT, v. 2, n. 1, p. 93-109, 2013.

NEVES, E. R. C. et al. A motivação de alunos no contexto da progressão continuada. Psicologia: teoria e pesquisa, 2004.

NG, Y. H.; LAI, S. P.; SU, Z. P.; YAP, J. Y.; TEOH, H. Q.; LEE, H. (2017). Factors influencing accounting students' career paths. Journal of Management Development, v. 36, n. 3, p. 319-329, 2017.

NOSSA, V. Formação do corpo docente dos cursos de graduação em contabilidade no Brasil: uma análise crítica. Caderno de Estudos, n. 21, p. 01-20, 1999.

OLIVEIRA, Ê. S. Motivação no ensino superior: estratégias e desafios. Revista Contexto \& Educação, v. 32, n. 101, p. 212-232, 2017.

OLIVEIRA, P. A. de, et al. Motivação sob a perspectiva da Teoria da Autodeterminação: um estudo da motivação de alunos do curso de Ciências Contábeis da Universidade Estadual de Montes Claros. In: Congresso USP de Iniciação Científica em Contabilidade. 2010.

PILETTI, N. Psicologia educacional. São Paulo: Ática, 1997.

RAMOS, S. I. V. Motivação acadêmica dos alunos do ensino superior. Disponível em: <http://www.psicologia.pt/artigos/textos/A0677.pdf>. Acesso em 4 jul. 2017.

RUIZ, V. M. Estratégias motivacionais: Estudo exploratório com universitários de um curso noturno de administração. Psicologia escolar e educacional, v. 8, n. 2, p. 167-177, 2004.

SCHIFFMAN, L. G.; KANUK, L. L. Comportamento do consumidor. 6. ed. Rio de Janeiro: LTC, 2000.

SILVA, T. L. F. et al. A motivação no Ensino Superior: um estudo com alunos dos cursos de Administração e Direito. Revista Gestão em Análise, v. 3, n. 1/2, p. 104-113, 2014.

SILVA, W. R. da, et al. Escolha do curso de administração: uma análise comparativa entre uma instituição pública e uma instituição privada. Encontro Nacional dos Programas de Pós-Graduação em Administração, v. $29,2005$.

SOUKI, G. Q.; PEREIRA, C. A. Satisfação, motivação e comprometimento de estudantes de administração: um estudo com base nos atributos de uma instituição de ensino superior. Encontro Nacional dos Programas de Pós-graduação em Administração, v. 28, 2004.

VALENTE, J. A. Formação de educadores para o uso da informática na escola. Campinas: UNICAMP, 2001.

WECHSLER, S. M. Manual estilos de pensar e criar. São Paulo: LAMP/PUC, 2006. 